\title{
Research on Practice Methods of Complex Aircraft Requirement Management
}

\author{
Zhixiao Sun, Dong Kan, Yang Bai, and Yuanjie Lu
}

\begin{abstract}
The development of complex aircraft is complicated system engineering. Facing to the requirements exponential growth of complex aircraft, manufacturers put forward stringent standard to requirement quality control, therefore, it is very urgent to explore a suitable method for requirement management of complex aircraft development. The paper uses the development of complex aircraft as an example based on system engineering method, discusses the engineering application practice of requirement management technology from requirement acquisition, attribute and traceability, verification and validation, change control. Research shows when implementing requirement management method in this paper on complex aircraft, it can effectively improve the integrity, systemic, validity, coherence of requirement, further enhance the quality of requirement and efficiency of management, and the development cycle is shortened and the cost is reduced in the future.
\end{abstract}

Z. Sun $(\bowtie) \cdot$ D. Kan · Y. Bai · Y. Lu

INCOSE CSEP, Shenyang Aircraft Design and Research Institute (SADRI), AVIC, No. 40 Tawan Road, Shenyang, Liaoning, China

Y. Bai

e-mail: baijordon@163.com

$\mathrm{Y} . \mathrm{Lu}$

e-mail: plough5221@sina.com 